\title{
Cooperar para aprender: contributos para o desenvolvimento de competências sociais em crianças da Educação Pré-escolar e do $1^{\circ}$ Ciclo do Ensino Básico
}

\section{Cooperative Learning in the development of social competences in children of the Preschool Education and of the 1st Cycle of the Basic Teaching}

\author{
Ana Rita Ferreira*, Ivone Neves ** \\ *Centro de Caridade Nossa Senhora do Perpétuo Socorro, ** Escola Superior de Educação de Paula Frassinetti e Universidade \\ Lusófona de Humanidades e Tecnologias
}

\begin{abstract}
Resumo
O estudo que se apresenta pretende averiguar os contributos da Aprendizagem Cooperativa no desenvolvimento de competências sociais em crianças da Educação Pré-Escolar e do $1^{\circ}$ Ciclo do Ensino Básico. O mesmo foi desenvolvido com vista a perspetivarmos quais as estratégias a implementar para promover o desenvolvimento de skills de cooperação nas crianças. Os resultados obtidos revelaram um impacto positivo da aprendizagem cooperativa no desenvolvimento de vários skills, na medida em que através da intervenção e desenvolvimento do trabalho em grupos cooperativos, as crianças evidenciam uma maior motivação, demonstrando desenvolver competências de entreajuda, skills sociais (poder argumentativo/espírito crítico) e skills de cooperação (aceitação da opinião do outro).

Palavras chave: Aprendizagem cooperativa, Grupos Cooperativos, Entreajuda
\end{abstract}

\begin{abstract}
The study that she present intends to discover the contributos of the Cooperative Learning in the development of social competences in children of the Preschool Education and of the 1st Cycle of the Basic Teaching. The same was developed with view the perspective which the strategies to implement to promote the development of cooperation skills in the children. The obtained results revealed a positive impact of the cooperative learning in the development of several skills, in the measure in that through the intervention and development of the work in cooperative groups, the children evidence a larger motivation, demonstrating to develop entreajuda competences, social (to can argumentative / spirit criticizes) skills and cooperation (acceptance of the opinion of the other) skills

Keywords: Cooperative Learning, Cooperative Groups, Self-help
\end{abstract}

\section{Método}

Ao falarmos da preparação das crianças para a vida em sociedade e da preparação para uma vida democrática, estamos, à partida, de forma implícita a referir-nos às relações e interações que as crianças começam desde cedo a criar com o outro. A forma como vêem e entendem o mundo, como respeitam a opinião do outro, como ajudam ou não o outro, deve começar a ser desenvolvida quer na educação Pré-Escolar, quer no $1^{\circ} \mathrm{Ciclo} \mathrm{do} \mathrm{Ensino} \mathrm{Básico.} \mathrm{É} \mathrm{neste} \mathrm{sentido} \mathrm{que} \mathrm{aprender} \mathrm{a}$ cooperar deve fazer parte do trabalho realizado pelo educador e pelo professor, para que através da cooperação se propiciem aprendizagens e se alcancem competências tanto pessoais como sociais.

No presente estudo privilegiamos adotar uma metodologia de natureza qualitativa, uma vez que, e segundo Tuckman (2000), este método privilegia a situação natural como fonte de dados, sendo o investigador $\mathrm{o}$ instrumento-chave da recolha dos mesmos. Partindo da ideia do mesmo autor, a utilização de uma metodologia qualitativa vai essencialmente ao encontro de um significado das coisas, ou seja, em busca de resposta para o "porquê" e para "o quê".

Considerando que é indispensável estabelecer um fio condutor que nos dirija e dê propósito à investigação, foi estabelecida a seguinte pergunta de partida: Quais as estratégias a implementar para promover $o$ desenvolvimento de skills de cooperação nas crianças? Subjacente à pergunta de partida, resultam dois objetivos primordiais: percecionar os skills que as crianças desenvolvem no trabalho cooperativo e identificar as vantagens decorrentes da intervenção educativa face à implementação da Aprendizagem Cooperativa.

Esta investigação - ação, nomeada como “(...) uma família de metodologias de investigação que incluem acção (ou mudança) e investigação (ou compreensão) ao mesmo tempo, utilizando um processo cíclico ou em espiral, que alterna entre acção e reflexão crítica" (Coutinho e tal, 2009, p. 360) foi assumindo esse mesmo pressuposto de refletir e interrogar as práticas educativas ocorridas em contexto à luz da temática - Aprendizagem Cooperativa. Desta forma confirmamos assim a natureza da investigação - ação, como ato de "exploração reflexiva que o professor faz da sua prática, contribuindo dessa forma não só para a resolução de problemas como também (...) para a planificação e introdução de alterações dessa e nessa mesma prática" (ibidem, p. 360). 


\section{Participantes}

A investigação decorreu em duas instituições, em momentos distintos, sendo que uma instituição refere-se ao contexto de Pré-Escolar e a outra ao contexto de $1 .^{\circ}$ Ciclo do Ensino Básico $\left(1^{\circ} \mathrm{CEB}\right.$.) Caracterizando de forma breve cada instituição, podemos avançar que ambas as instituições integravam as valências de Pré-Escolar e o $1^{\circ}$ ciclo do Ensino Básico e estavam localizadas no concelho do Porto. A instituição onde decorreu a intervenção em Pré-Escolar, tratava-se de uma instituição privada de cariz religioso. Por outro lado, a intervenção decorrida em $1^{\circ}$ Ciclo do Ensino Básico ocorreu numa escola pertencente à rede pública. A intervenção em contexto Pré-Escolar, decorreu numa sala de 3/4 anos, formada por vinte e seis crianças, sendo dez do sexo feminino e os restantes dezasseis do sexo masculino. Tratando-se de uma sala de um grupo misto, no que respeita à faixa etária, cinco das vinte e seis crianças correspondem ao grupo dos três anos e as restantes ao grupo dos quatro anos. A intervenção em contexto de $1^{\circ}$ Ciclo, incidiu numa turma de $1^{\circ}$ ano, constituída por vinte e seis alunos, sendo catorze do sexo feminino e doze do sexo masculino. Os alunos encontravam-se entre os cinco e os sete anos de idade.

\section{Instrumentos}

No decorrer da investigação a observação revelou-se capital, uma vez que este procedimento possibilita ao observador recolher dados capazes de fornecer informações significativas relativas a um determinado acontecimento ou aspeto. Ao encontro desta ideia, Tuckman (2000) salienta que a observação é o dispositivo mais utilizado para a recolha de dados. Deste modo, "a observação permite o conhecimento directo dos fenómenos tal como eles acontecem num determinado contexto (...) A observação ajuda a compreender os contextos, as pessoas que nele se movimentam e as suas interacções" (Máximo-Esteves, 2008, p. 87). Esta fase do trabalho de observação consiste na estruturação de instrumentos adequados à recolha de dados, capazes de nos ajudarem a obter indicadores que vão ao encontro dos objetivos estabelecidos para a investigação. Assim sendo, estamos perante uma observação direta, que segundo Quivy \& Campenhoudt (1998), o investigador tem como intenção proceder diretamente à recolha de dados. Uma vez que a observação direta assume múltiplos formatos, para apoiar a investigação, foram selecionados instrumentos de recolha de dados que comprovam, a intervenção realizada nos contextos e os resultados que essa mesma intervenção evidenciou. Os registos de incidentes críticos e as amostragens de acontecimentos, foram formatos de observação utilizados para registar e refletir os dados da observação. A par destes, foram ainda utilizados registos de atividades significativas e registos fotográficos, que pretendiam evidenciar os dados obtidos fruto da intervenção. De forma a valorizar a autoavaliação das crianças, relativamente ao trabalho realizado, foi também utilizada uma grelha de auto-avaliação. Esta foi uma adaptação de uma grelha de auto-avaliação, presente no livro, Métodos de Aprendizagem Cooperativa para o Jardim-de-Infância, da autoria de José Lopes e Helena
Santos Silva (2008). Esta grelha de auto-avaliação é sugerida como forma de avaliar a participação das crianças numa dada atividade, face à utilização do método de aprendizagem cooperativa Círculos concêntricos. Segundo Lopes e Silva (2008), “(...) é um método simples que permite às crianças terem uma discussão estruturada com vários colegas num curto espaço de tempo. Pode desenvolver a ideia de movimento na sala de atividade com um fim específico" (Lopes \& Silva, 2008, p. 120).

E para percecionarmos a opinião das crianças, recorreu-se à realização de uma entrevista conversa com os participantes.

\section{Análise dos dados}

De acordo com a análise dos dados recolhidos, foi possível verificar que as crianças do Pré-escolar e os alunos do $1^{\circ} \mathrm{CEB}$, se envolvem no trabalho em grupo de forma muito entusiasta, estes dados foram verificados tanto nos registos das atividades significativas, como nos comentários e intervenções que as crianças faziam no decorrer das atividades.

"E: E conseguem aprender uns com os outros não é?

Todos: Sim!

L: Se nós trabalharmos em grupo aprendemos todos". (excerto da entrevista conversa EPE)

No contexto da Educação Pré-escolar, uma vez que grande parte das propostas partem dos interesses das crianças, também parece-nos ser um fator que influencia e facilita a forma como se posicionam perante um trabalho e como se dedicam para a concretização do mesmo. Por outro lado, no $1^{\circ} \mathrm{CEB}$, no trabalho realizado em grupo é visto com enorme satisfação, uma vez que os alunos só começaram a trabalhar em grupo, a partir do momento em que se iniciou esta intervenção, recorrendo a práticas de trabalho cooperativo pela primeira vez. Pode dizer-se, que através das experiências proporcionadas ao longo das intervenções desenvolvidas nos dois contextos, foram criados momentos de Aprendizagem Cooperativa, que não aconteciam anteriormente. Ao longo da análise dos dados, verificou-se o quanto as crianças do Pré-Escolar e os alunos do $1^{\circ} \mathrm{CEB}$ gostam de participar manifestam agrado, por atividades que envolvem o trabalho cooperativo e demonstram vontade de realizar mais atividades recorrendo a esta metodologia, este dado é evidenciado nas grelhas de auto-avaliação que as crianças preenchiam, no final de cada trabalho cooperativo. Estes dois aspetos (agrado e vontade de realizar atividades cooperativas) parecem estar relacionados, pois quando a criança gosta de realizar determinado trabalho, tende a querer repetir, e a sua predisposição para o fazer é maior, do que se não tivesse gostado da atividade. Neste sentido, julgamos que as crianças de facto se interessam pelo trabalho quer em pares, quer em pequenos grupos. Tendencialmente os resultados parecem apontar também para uma ligação entre $o$ interesse pela atividade e o esforço nela implicado, ou seja, quando as crianças/alunos gostam do que estão a fazer tendem a esforçar-se mais naquilo que estão a fazer. Também apontamos o facto de quando os alunos estão em grupo, a dedicação de empregam no 
trabalho é maior, do que quando estão a realizar um trabalho sozinhos.

Outro aspeto que importa destacar é a entreajuda entre as crianças/alunos que formam um grupo. Quanto mais à vontade as crianças/alunos se sentem, quanto mais envolvidas/os estão em determinada atividade, quanto mais se nota que a criança/aluno está a gostar do trabalho que está a fazer, mais se nota a entreajuda entre o grupo. A entreajuda também é muito influenciada pela comunicação que o próprio grupo estabelece. Se os membros de um grupo não conversam, não discutem hipóteses e ideias, torna-se difícil ajudarem-se uns aos outros, porque acaba por não haver espírito de grupo. Esta competência nem sempre existiu, mas foi evoluindo à medida que novas experiências eram proporcionadas, ou seja, sempre que as crianças/alunos eram desafiadas a fazer um trabalho em grupo. Progressivamente as crianças do Pré-Escolar e os alunos do $1^{\circ} \mathrm{CEB}$, foram aprendendo a ajudar o outro, a ouvir o outro, a respeitar e a ter espírito de equipa. $\mathrm{O}$ facto de os grupos de trabalho terem sido criados da forma mais heterogénea possível, permitiu também criar situações em que a entreajuda era fundamental para o sucesso do grupo. Mais concretamente isto acontecia quando num grupo havia crianças/ alunos mais novas/os e outras/os mais velhas/os. Nos dois contextos, foi sempre possível verificar que as crianças/alunos mais velhas/os ajudavam as/os mais novas/os, nas tarefas pessoais como apertar o casaco, apertar os cordões, dando indicações, ajudando com a manipulação dos materiais ou até explicando um exercício. Também a entrevista - conversa realizada nos dois contextos permitiu perceber-se que de facto, no caso do Pré-escolar, as crianças preferem tanto nas brincadeiras, como nos trabalhos realizados em sala, estar com outras crianças, considerando que se podem ajudar umas às outras. No caso dos alunos do $1^{\circ} \mathrm{CEB}$, demonstraram a mesma opinião, preferindo trabalhar em grupo. Foi possível verificar também que as crianças e os alunos acreditam que é mais fácil fazer os trabalhos juntos, porque os fazem mais rápido e têm ajuda dos colegas. As crianças e os alunos reconhecem ainda, que aprendem uns com os outros. Este dado é surpreendente, pois parece revelar o que no inicio da intervenção chamou à atenção, ou seja, o facto destas crianças e destes alunos não estarem habituados a trabalhar cooperativamente. Ao longo das atividades que foram proporcionadas, as crianças e os alunos começaram a adquirir hábitos de auto e hetero avaliação, que se espelham tanto nos comentários e reflexões que foram fazendo, face aos trabalhos realizados, como nos registos por eles efetuados. A autoavaliação revelou-se ser uma estratégia que promove o desenvolvimento de skills de cooperação. Também o debate em grande grupo e a troca de ideias que os trabalhos cooperativos proporcionam, contribuem de forma significativa para o desenvolvimento destes skills, uma vez que as crianças aprendem a ouvir o outro e a respeitar a opinião do outro. As atividades implementadas também permitiram que o espírito de equipa e a entreajuda se proporcionassem.

\section{Reflexão Final}

Diante da investigação produzida, importa refletir sobre a pergunta de partida que orientou todo o processo: Quais as estratégias a implementar para promover o desenvolvimento de skills de cooperação nas crianças? A finalidade desta questão foi percecionar o desenvolvimento das crianças e dos alunos após o contacto com o trabalho cooperativo. Desta forma, entenderíamos os impactos e as vantagens inerentes a esta prática. Com vista a deixar evidentes algumas ideias essenciais, reforça-se a ideia de Freixo e Fontes (2004), em que consideram que “(...) os conflitos, as oposições e a diversidade dos vários pontos de vista, constituem a trama de fundo da cooperação.” (p.60). De facto, esta variedade de pensamento que o trabalho cooperativo proporcionou dentro dos grupos, levou a que os seus elementos aceitassem a opinião do outro e a respeitassem. Desta forma, é possível afirmar que este foi um dos skills de cooperação desenvolvido pelas crianças. Importa salientar que o debate em grande grupo, foi uma das estratégias implementadas que proporcionou $\mathrm{o}$ desenvolvimento deste skill.

A avaliação, foi uma estratégia encontrada que proporcionou uma gradual evolução de competências de cooperação. Apontada como um dos elementos fundamentais da aprendizagem cooperativa, pode-se de facto comprovar que "(...) para que o processo de aprendizagem melhore de forma sustentada, as crianças devem avaliar se as suas ações são positivas ou negativas e tomar decisões sobre as condutas a manter ou a modificar em ocasiões futuras" (Lopes \& Silva, 2008, p.21). Neste sentido, a avaliação foi sempre valorizada no término das atividades realizadas, pois assim eram originados instantes de reflexão sobre o trabalho realizado, que levaram as crianças a argumentar porque fizeram assim, mas também a criticar o trabalho que realizaram, uma vez que também souberam apontar melhorias a fazer, souberam apontar o que correu bem e o que correu menos bem. Uma vez mais, pode considerar-se que o poder argumentativo e o espírito crítico foram também skills desenvolvidos. A interação, resultante das oportunidades que as crianças tiveram para trabalhar cooperativamente, proporcionou ainda a aprendizagem de um hábito essencial, e que consideramos ser também um skill de cooperação desenvolvido, a entreajuda. Não podemos deixar de referir, a importância do educador/professor, que tem um papel essencial, na medida em que, é esperado que o mesmo alargue oportunidades educativas. Neste caso concreto, esperamos que este favoreça uma aprendizagem cooperada, em que as crianças são envolvidas no trabalho, de forma a aprenderem umas com as outras.

\section{Referências}

Coutinho, C. P., Sousa, A., Dias, A., Bessa, F., Ferreira, M. J.,\& Vieira, S. (2009). Investigação - acção: metodologia preferencial nas práticas educativas. Revista Psicologia, Educação e Cultura, XIII (2), 355-379. 
Freixo, O. \& Fontes, A. (2004). Vygotsky e a Aprendizagem Cooperativa. Lisboa: Livros Horizonte. Lopes, J. \& Silva, H. (2008). Métodos de Aprendizagem Cooperativa para o Jardim - de - Infância. Porto: Areal Editores.

Máximo - Esteves, L. (2008). Visão Panorâmica da Investigação - Acção. Porto: Porto Editora.

Quivy, R. \& Campenhoudt, L. (1998). Manual de Investigação em Ciências Sociais. Lisboa: Gradiva.

Tuckman, B.W. (2000). Manual de Investigação e Educação. Lisboa: Fundação Calouste Gulbenkian. 